\title{
The Associations of Asthma Symptoms With Active and Passive Smoking in Hong Kong Adolescents
}

\author{
Kwok-Kei Mak PhD, Roger Chun-Man Ho MRCPsych, and Jeffrey R Day PhD
}

\begin{abstract}
BACKGROUND: Tobacco smoke has detrimental effects on the respiratory system. This study investigated the associations of active and passive smoking with asthma symptoms in Hong Kong adolescents. METHODS: A total of 6,494 Hong Kong secondary school students, with a mean \pm SD age of 15.0 \pm 1.21 years, participated in the Health Related Behavior General Survey in 2000-2001. They reported their demographic factors (sex, age, housing type, district of living), lifestyles (smoking, drinking, extracurricular sports, eating), and asthma symptoms (exercise-induced bronchospasm [EIB] and nocturnal cough) in the questionnaire. In addition, number of smoking parents (none/one/both) and presence of a smoking best friend (yes/no) were assessed. Logistic regression models were used to determine the odds ratios (OR) of frequently having the asthma symptoms for different smoking status of students, parents, and best friend, with adjustment for demographic factors and lifestyles. RESULTS: The prevalence of former, light, and heavy smokers was $17.5 \%$, $7.7 \%$, and $1.0 \%$, respectively. Moreover, $35.1 \%$ of the participants had one and $3.8 \%$ had 2 parents who smoked. Heavy smokers were more likely to experience EIB with OR (95\% CI) of 2.27 (1.30-3.97) and nocturnal cough with OR (95\% CI) of 3.45 (1.52-7.81), as well as both symptoms with OR $(95 \%$ CI $)=4.69(1.88-11.73)$ when compared to those who never smoked. The corresponding OR $(95 \% \mathrm{CI})$ for having at least one smoking parent and a smoking best friend was 1.45 (1.17-1.81), 1.61 (1.06-2.42), and 2.43 (1.37-4.31), when compared with those without a parent or best friend who smoked. CONCLUSIONS: Adolescents who are heavy smokers and having parents and a best friend who smoke are more likely than others to have asthma symptoms. Both active and passive smoking are related to asthma symptoms in adolescents. Key words: active smoking; passive smoking; asthma symptoms; adolescents. [Respir Care 2012;57(9):1398-1404. (C) 2012 Daedalus Enterprises]
\end{abstract}

\section{Introduction}

Asthma is the one of the most common chronic diseases in children. ${ }^{1}$ About 1 out of 11 United States children

Dr Mak is affiliated with the Department of Community Medicine and School of Public Health, Faculty of Medicine; and Dr Day is affiliated with the Faculty of Education, University of Hong Kong, Pokfulam, Hong Kong. Dr Ho is affiliated with the Department of Psychological Medicine, Yong Loo Lin School of Medicine, National University of Singapore, Republic of Singapore.

The authors have disclosed a relationship with the Action Committee Against Narcotics of the Hong Kong government.

Correspondence: Kwok-Kei Mak PhD, Department of Community Medicine and School of Public Health, Faculty of Medicine, University of Hong Kong, 21 Sassoon Road, Pokfulam, Hong Kong. E-mail: kkmak@graduate.hku.hk.

DOI: $10.4187 /$ respcare. 01548 currently have asthma, causing a substantial burden on the healthcare system. ${ }^{2}$ Tobacco smoke contains more than 4,000 harmful chemical compounds. Both active smoking ${ }^{3}$ and exposure to secondhand smoke ${ }^{4-6}$ lead to respiratory symptoms in adolescents. Exercise-induced bronchospasm $(\mathrm{EIB})^{7}$ and nocturnal cough are the major asthma symptoms $^{8}$ related to active smoking ${ }^{9,10}$ and passive smoking ${ }^{11}$

See the Related Editorial on Page 1528

in adolescents. While partners are the major source of secondhand smoke for adults, ${ }^{12}$ adolescents' main exposure to secondhand smoke is from their parents ${ }^{5,13,14}$ and peers. ${ }^{15-17}$ The associations of asthma symptoms with active and passive smoking in adolescents are complex, ${ }^{18}$ and information in the Chinese populations is limited. 
The prevalence of asthma among adolescents in Hong Kong is relatively higher than those living in the mainland China or in the West, ${ }^{19}$ although a decreasing trend was observed in recent years. ${ }^{20}$ With a dense living environment in Hong Kong, the impact of passive smoke on the respiratory health in adolescents may be even more severe. This study investigated the additive associations of asthma symptoms with active smoking and passive smoking exposure in Hong Kong adolescents.

\section{Methods}

In this study, stratified sampling was used to select schools to represent sex, academic ability, and administrative districts in the Hong Kong school system. Any schools refusing to participate were replaced by another school with similar characteristics. A total of 6,494 students with mean \pm SD age of $15.0 \pm 1.21$ years $(92.7 \%$ from grammar and $7.3 \%$ from vocational schools) participated in the Health Related Behavior General Survey in 2000-2001, with a response rate of 95\%. The Health Related Behavior General Survey, licensed from the Schools Health Education Unit of the University of Exeter in the United Kingdom, was developed to assess health-related behaviors, including physical activity and risky behaviors such as substance use. ${ }^{21}$ Parental consent was sought, and students were briefed by trained teachers that participation was voluntary. Students completed their questionnaires in class, and the procedures for ensuring anonymity were also described to them. Ethics approval was obtained from the university ethics committee. Details of the administration of the study have been reported elsewhere.22,23

Students reported their basic information, including sex, age, housing type, and district of living in the questionnaire. The smoking status of the students was assessed by the question "Which of the following statements describe your smoking status the best?" with options: A: I have never smoked at all, not even a puff; B: I have tried smoking once or twice; C: I used to smoke, but I don't now; D: I smoke occasionally; and E: I smoke regularly. They were then classified into never (option A), former (options B and C), and current (options D and E) smokers. Smoking intensity was assessed by the number of cigarettes consumed in the last week. Current smokers were further classified into the light (smoked $<100$ cigarettes in last week) and heavy (smoked $\geq 100$ cigarettes in last week) smokers.

The question to ascertain the smoking status of the parents and the best friend was "Please select those who smoke regularly?" with options of father, mother, and best friend. The parental smoking status was then recoded into "both of them smoke," "one of them smoke," and "none of them smoke."

\section{QUICK LOOK}

\section{Current knowledge}

Exposure to active or passive smoking is associated with lung dysfunction in adolescents and increases risk for reactive airway diseases.

\section{What this paper contributes to our knowledge}

Adolescents who are heavy smokers, have parents who smoke, or have a best friend who smokes have an increased risk of asthma symptoms.

The 2 major symptoms of asthma assessed were: EIB (When you run, do you wheeze or feel difficulty in breathing?) and nocturnal cough (Do you experience sleep disturbance due to coughing?) with options of A) never, B) seldom, C) often, and D) very often. Similar outcome measures have been used in other adolescent studies. ${ }^{24}$ In addition, students' lifestyles, including exercise, eating, and drinking, were examined. Students' sports participation was assessed by a checklist of sporting events that they performed at least weekly.

Their eating habits were assessed by a single item: "Do you consider your health when making food choices?" A) never, B) sometimes, C) often, D) very often, E) always. Moreover, number of days of drinking alcohol in a week $(0-7 \mathrm{~d})$ were reported and recategorized into weekly (1-7 d) or non-weekly (0 d) in the analysis. The internal validity of the outcome measures was assessed by their relations, with number of days taking prescribed medicine for asthma, "How many days have you used medicine for asthma? (0-7 d)," using analysis of variance.

In the main analysis, responses to EIB and nocturnal cough were dichotomized into "frequent" (very often/often) and "infrequent" (seldom/never) groups. Logistic regression models were used to determine the ORs of having frequent (vs infrequent) EIB and nocturnal cough for different smoking status of the students, and their parents and best friend. In order to examine the combined effects of active and passive smoking on having frequent respiratory symptoms, a new variable combining the smoking status of parents (none/at least one) with the smoking status of their best friend (yes/no) was created and entered into the repeating logistic regression analyses. Sex, age, housing type, and district of living were adjusted in all the models.

\section{Results}

In Table 1, the prevalence of former smokers was $19.1 \%$ in boys and $15.8 \%$ in girls. The respective prevalence of light smokers was $8.4 \%$ and $7.0 \%$, and the respective prevalence of heavy smokers was $1.7 \%$ and $0.3 \%$. Regarding 
The Associations of Asthma Symptoms With Active and Passive Smoking

Table 1. Basic Characteristics, Lifestyles, and Asthma Symptoms of Students, and Smoking Status of Parents and Best Friend

\begin{tabular}{|c|c|c|c|}
\hline & $\begin{array}{c}\text { Boys, } \\
\text { no. }(\%) \\
(n=3,284)\end{array}$ & $\begin{array}{c}\text { Girls, } \\
\text { no. }(\%) \\
(n=3,210)\end{array}$ & $\begin{array}{c}\text { All, } \\
\text { no. }(\%) \\
(n=6,494)\end{array}$ \\
\hline \multicolumn{4}{|l|}{ Age Group, y } \\
\hline 13 or below & $151(4.6)$ & $49(1.5)$ & $200(3.1)$ \\
\hline 14 & $1,067(32.5)$ & $1,430(44.5)$ & $2,497(38.5)$ \\
\hline 15 & $1,128(34.3)$ & $1,290(40.2)$ & $2,418(37.2)$ \\
\hline 16 & $328(10.0)$ & $310(9.7)$ & $638(9.8)$ \\
\hline 17 & $134(4.1)$ & $97(3.0)$ & $231(3.6)$ \\
\hline 18 or above & $476(14.5)$ & $34(1.1)$ & $510(7.9)$ \\
\hline \multicolumn{4}{|l|}{ Housing } \\
\hline Private & $1,491(45.4)$ & $1,312(40.9)$ & $2,803(43.2)$ \\
\hline Public or others & $1,793(54.6)$ & $1,898(59.1)$ & $3,691(56.8)$ \\
\hline \multicolumn{4}{|l|}{ Participating in Extracurricular Sports } \\
\hline None & $1,156(35.2)$ & $1,566(48.8)$ & $2,722(41.9)$ \\
\hline $1-2$ & $1,410(42.9)$ & $1,219(38.0)$ & $2,629(40.5)$ \\
\hline 3 or above & $718(21.9)$ & $425(13.2)$ & $1,143(17.6)$ \\
\hline \multicolumn{4}{|l|}{ Eating Healthy } \\
\hline Never/seldom & $2,217(67.5)$ & $2,220(69.2)$ & $4,437(68.3)$ \\
\hline Sometimes/always & $1,067(32.5)$ & $990(30.8)$ & $2,057(31.7)$ \\
\hline \multicolumn{4}{|l|}{ Weekly Drinking } \\
\hline No & $2,542(77.4)$ & $2,514(78.3)$ & $5,056(77.9)$ \\
\hline Yes & $742(22.6)$ & $696(21.7)$ & $1,438(22.1)$ \\
\hline \multicolumn{4}{|l|}{ Smoking Status of Student } \\
\hline Never & $2,326(70.8)$ & $2,466(76.8)$ & $4,792(73.8)$ \\
\hline Former & $626(19.1)$ & $508(15.8)$ & $1,134(17.5)$ \\
\hline \multicolumn{4}{|l|}{ Current } \\
\hline Light smokers $(<100$ cigarettes in last week) & $276(8.4)$ & $226(7.0)$ & $502(7.7)$ \\
\hline Heavy smokers ( $\geq 100$ cigarettes in last week) & $56(1.7)$ & $10(0.3)$ & $66(1.0)$ \\
\hline \multicolumn{4}{|l|}{ Smoking Status of Parents } \\
\hline None of them are smokers & $2,008(61.1)$ & $1,960(61.1)$ & $3,968(61.1)$ \\
\hline Either one is smoker & $1,146(34.9)$ & $1,131(35.2)$ & $2,277(35.1)$ \\
\hline Both are smokers & $130(4.0)$ & $119(3.7)$ & $249(3.8)$ \\
\hline \multicolumn{4}{|l|}{ Presence of a Smoking Best Friend } \\
\hline No & $2,454(74.7)$ & $2,595(80.8)$ & $5,049(77.7)$ \\
\hline Yes & $830(25.3)$ & $615(19.2)$ & $1,445(22.3)$ \\
\hline \multicolumn{4}{|l|}{ Exercise-Induced Bronchospasm } \\
\hline Never & $1,168(35.6)$ & $829(25.8)$ & $1,997(30.8)$ \\
\hline Occasionally & $1,607(48.9)$ & $1,746(54.4)$ & $3,353(51.6)$ \\
\hline Often & $316(9.6)$ & $382(11.9)$ & $382(10.7)$ \\
\hline Very often & $193(5.9)$ & $253(7.9)$ & $253(6.9)$ \\
\hline \multicolumn{4}{|l|}{ Nocturnal Cough } \\
\hline Never & $2,290(69.7)$ & $1,969(61.3)$ & $4,259(65.6)$ \\
\hline Seldom & $862(26.2)$ & $1,136(35.4)$ & $1,998(30.8)$ \\
\hline Often & $77(2.3)$ & $69(2.1)$ & $146(2.2)$ \\
\hline Very often & $55(1.7)$ & $36(1.1)$ & $146(1.4)$ \\
\hline $\begin{array}{l}\text { Frequent exercise-induced bronchospasm and nocturnal cough } \\
\text { (often/very often) }\end{array}$ & $57(2.0)$ & $44(1.4)$ & 91 (1.7) \\
\hline $\begin{array}{l}\text { Number of days prescribed medicine for asthma was taken } \\
\text { (last week) (mean) }\end{array}$ & $0.11(0.67)$ & $0.08(0.60)$ & $0.09(0.63)$ \\
\hline
\end{tabular}

parental smoking status, $35.1 \%$ of students had one parent who smoked, and $3.8 \%$ had two. A total of $22.3 \%$ of the students reported the presence of a best friend who smoked. Moreover, $17.6 \%$ and $3.6 \%$ of them frequently experi- enced exercise-induced wheeze and nocturnal cough, respectively. The prevalence of weekly drinking was $22.1 \%$, participating in any extracurricular sports was $58.1 \%$, and sometimes/always eating healthily was $31.7 \%$. In Table 2 , 


\section{The Associations of Asthma Symptoms With Active and Passive Smoking}

Table 2. Number of Days Prescribed Medicine for Asthma Was Taken in the Past 7 Days Among Students With Asthma Symptoms

\begin{tabular}{lc}
\hline \hline & $\begin{array}{c}\text { Days, } \\
\text { mean } \pm \text { SD }\end{array}$ \\
\hline Exercise-Induced Bronchospasm & $0.05 \pm 0.43$ \\
$\quad$ Never & $0.06 \pm 0.50$ \\
$\quad$ Seldom & $0.21 \pm 0.94$ \\
Often & $0.34 \pm 1.28$ \\
$\quad$ Very often & $<.001$ \\
$P^{*}$ & \\
Nocturnal Cough & $0.05 \pm 0.45$ \\
$\quad$ Never & $0.09 \pm 0.62$ \\
Seldom & $0.75 \pm 1.78$ \\
Often & $0.99 \pm 2.06$ \\
$\quad$ Very often & $<.001$ \\
$P^{*}$ & \\
Frequent Exercise-Induced Bronchospasm and & \\
$\quad$ Nocturnal Cough (often/very often) & $0.07 \pm 0.56$ \\
No & $1.12 \pm 2.16$ \\
Yes & $<.001$ \\
$P^{*}$ & \\
\hline$* P$ for analysis of variance. & \\
\hline
\end{tabular}

the mean number of days taking anti-asthma medicine increased significantly with the frequency of having EIB or nocturnal cough, or both.

In Table 3, the prevalence of having frequent EIB increased from former $(17.9 \%)$, to light smokers $(20.9 \%)$, and heavy smokers $(31.8 \%)$. The respective prevalence for nocturnal cough also increased from $5.5 \%$ to $6.6 \%$ and $12.1 \%$. When compared to the never smokers, heavy smokers were significantly more likely to experience frequent EIB with odds ratio (OR) (95\% CI) of 2.33 (1.34-4.06). When compared to never smokers, the OR (95\% CI) of frequent nocturnal cough increased significantly from former (1.71 [1.24-2.37]), to light (1.76 [1.12-2.77]) and heavy (3.31 [1.46-7.50]) smokers, with $P$ for trend of .03. The OR $(95 \% \mathrm{CI})$ of frequent EIB (1.16 [1.01-1.33] for one, 1.43 [1.05-1.97] for two), nocturnal cough (1.25 [0.951.65] for one, 1.79 [1.06-3.02] for two), and both symptoms (1.43 [0.96-2.14] for one, 2.06 [1.00-4.25] for two) all increased significantly $(P<.05)$ with number of smoking parents. Having a smoking best friend was not independently associated with frequent EIB, nocturnal cough, or both, with non-significant ORs $(95 \% \mathrm{CI})$ of 1.12 (0.94-1.33), 1.21 (0.87-1.68), and 1.57 (0.99-2.49), respectively.

In Table 4, within the combinations of smoking status of parents and best friend, having no smoking parent but a smoking best friend had similar odds of having frequent respiratory symptoms as having at least one smoking parent but not a smoking best friend. Students having at least one smoking parent and a smoking best friend, however, were significantly more likely to experience frequent EIB with OR $(95 \% \mathrm{CI})$ of 1.45 (1.17-1.81), nocturnal cough with OR $(95 \% \mathrm{CI})$ of 1.61 (1.06-2.42), or both with OR $(95 \% \mathrm{CI})$ of $2.43(1.37-4.31)$ than those without any parents or best friends who smoked.

\section{Discussion}

When compared to current smokers, heavy smokers had a higher likelihood of frequent EIB, and both former and current (regardless of intensity) smokers had a higher likelihood of frequent nocturnal coughing. The higher odds of having EIB in current smokers than others in this study were in agreement with that reported in Korean adolescents. ${ }^{9}$ Similar increasing odds of nocturnal cough ${ }^{10}$ and breathing problems ${ }^{25}$ from never, to former and current smokers were also reported in other adolescent studies. Moreover, a higher likelihood of respiratory problems in higher smoking intensity students than the lower intensity group was also found in a longitudinal study. ${ }^{3}$ These results were supported by the experiments showing poorer lung function, as indicated by reduced $\mathrm{FEV}_{1}$ and forced expiratory flow during the middle half of the FVC maneuver $\left(\mathrm{FEF}_{25-75 \%}\right),{ }^{26}$ and exhaled NO level ${ }^{27}$ in adolescent smokers. Furthermore, a higher likelihood of nocturnal coughing ${ }^{28}$ and asthma ${ }^{29}$ for adolescents with parents who smoked was reported in surveys and experimental results. ${ }^{30}$ In addition, our results further showed that active and passive smoking have additive effects on asthma symptoms in adolescents, as reported in other studies. ${ }^{31,32}$ This is consistent with the finding that parents of children with asthma have better knowledge and practices regarding secondhand smoke. ${ }^{33}$ The associations between passive smoking and asthma symptoms among Hong Kong adolescents also suggest that the health authority should offer more education targeting parents to decrease second-hand smoke exposure.

There are several strengths and limitations in our study. The study relies on self-reported data to assess the smoking status and symptoms of asthma. Similar questions were used to assess the smoking status in other local adolescent studies. $^{34,35}$ Moreover, self-reported symptoms of asthma have been found to be reliable in repeated cross-sectional studies. ${ }^{36}$ The high correlations between the asthma symptoms and anti-asthma medication reported in adolescents ${ }^{37}$ in our study also provided good support for the internal validity of the outcome variables. While most of the existing studies on adolescent asthma did not investigate the impact of smoking intensity, our results imply that lower intensity of smoking is also detrimental to respiratory systems, although many adolescents probably underestimate its health risks. ${ }^{38}$ On the other hand, the causal relations between smoking and asthma symptoms are unclear with 


\section{The Associations of Asthma Symptoms With Active and Passive Smoking}

Table 3. Adjusted Odds Ratios of Frequent Asthma Symptoms for Smoking Status of Students, Parents, and Best Friend

\begin{tabular}{|c|c|c|c|c|c|c|c|c|c|}
\hline & \multicolumn{3}{|c|}{$\begin{array}{l}\text { Exercise-Induced } \\
\text { Bronchospasm }\end{array}$} & \multicolumn{3}{|c|}{ Nocturnal Cough } & \multicolumn{3}{|c|}{ Both Symptoms } \\
\hline & $\%$ & $\mathrm{OR} *(95 \% \mathrm{CI})$ & $P$ & $\%$ & $\mathrm{OR}^{*}(95 \% \mathrm{CI})$ & $P$ & $\%$ & $\mathrm{OR} *(95 \% \mathrm{CI})$ & $P$ \\
\hline \multicolumn{10}{|l|}{ Smoking Status of Students } \\
\hline Never & 17.0 & 1 & & 2.8 & 1 & & 1.4 & 1 & \\
\hline Former & 17.9 & $1.03(0.86-1.23)$ & .77 & 5.5 & $1.71(1.24-2.37)$ & .001 & 2.1 & $1.19(0.72-1.94)$ & .50 \\
\hline \multicolumn{10}{|l|}{ Current } \\
\hline Light smokers $(<100$ cigarettes in last week) & 20.9 & $1.20(0.93-1.55)$ & .17 & 6.6 & $1.76(1.12-2.77)$ & .02 & 2.4 & $1.10(0.55-2.21)$ & .79 \\
\hline Heavy smokers ( $\geq 100$ cigarettes in last week) & 31.8 & $2.33(1.34-4.06)$ & .003 & 12.1 & $3.31(1.46-7.50)$ & .004 & 10.6 & $4.57(1.83-11.43)$ & .001 \\
\hline$P$ for trend $\dagger$ & & & $<.001$ & & & .03 & & & .06 \\
\hline \multicolumn{10}{|l|}{ Smoking Status of Parents } \\
\hline Both are non-smokers & 16.6 & 1 & & 3.0 & 1 & & 1.3 & 1 & \\
\hline One is smoker & 18.8 & $1.16(1.01-1.33)$ & .03 & 4.3 & $1.25(0.95-1.65)$ & .12 & 2.1 & $1.43(0.96-2.14)$ & .08 \\
\hline Both are smokers & 23.3 & $1.43(1.05-1.97)$ & .03 & 7.6 & $1.79(1.06-3.02)$ & .03 & 4.0 & $2.06(1.00-4.25)$ & .04 \\
\hline$P$ for trend & & & .01 & & & .004 & & & .01 \\
\hline \multicolumn{10}{|l|}{ Presence of a Smoking Best Friend } \\
\hline No & 16.9 & 1 & & 3.1 & 1 & & 1.4 & 1 & \\
\hline Yes & 20.0 & $1.12(0.94-1.33)$ & .20 & 5.7 & $1.21(0.87-1.68)$ & .26 & 2.9 & $1.57(0.99-2.49)$ & .06 \\
\hline
\end{tabular}

Table 4. The Associations of Having Frequent Asthma Symptoms With Smoking Status of Students and Smoking Status Combinations of Parents and Best Friends

\begin{tabular}{|c|c|c|c|c|c|c|c|c|c|}
\hline & \multicolumn{3}{|c|}{$\begin{array}{l}\text { Exercise-Induced } \\
\text { Bronchospasm }\end{array}$} & \multicolumn{3}{|c|}{ Nocturnal Cough } & \multicolumn{3}{|c|}{ Both Symptoms } \\
\hline & $\%$ & OR* $(95 \% \mathrm{CI})$ & $P$ & $\%$ & OR* $(95 \% \mathrm{CI})$ & $P$ & $\%$ & $\mathrm{OR}^{*}(95 \% \mathrm{CI})$ & $P$ \\
\hline \multicolumn{10}{|l|}{ Student Smoking Status } \\
\hline Never & 17.0 & 1 & & 2.8 & 1 & & 1.4 & 1 & \\
\hline Former & 17.9 & $1.03(0.87-1.24)$ & .72 & 5.5 & $1.72(1.24-2.37)$ & .001 & 2.1 & $1.19(0.73-1.95)$ & .48 \\
\hline \multicolumn{10}{|l|}{ Current } \\
\hline Light smokers $(<100$ cigarettes in last week) & 20.9 & $1.20(0.93-1.56)$ & .16 & 6.6 & $1.78(1.13-2.79)$ & .013 & 2.4 & $1.11(0.55-2.23)$ & .77 \\
\hline Heavy smokers ( $\geq 100$ cigarettes in last week) & 31.8 & $2.27(1.30-3.97)$ & .004 & 12.1 & $3.45(1.52-7.81)$ & .003 & 10.6 & $4.69(1.88-11.73)$ & .001 \\
\hline$P$ for trend ${ }^{\dagger}$ & & & $<.001$ & & & .03 & & & .05 \\
\hline \multicolumn{10}{|l|}{ Number of regular smoking parents and best friends } \\
\hline No smoking parent + No smoking best friend & 16.5 & 1 & & 2.7 & 1 & & 1.2 & 1 & \\
\hline No smoking parent + Smoking best friend & 16.8 & $0.96(0.76-1.22)$ & .76 & 4.8 & $1.25(0.81-1.95)$ & .32 & 2.1 & $1.51(0.79-2.88)$ & .21 \\
\hline $\begin{array}{l}\text { At least one smoking parent }+ \text { No smoking best } \\
\text { friend }\end{array}$ & 17.7 & $1.09(0.94-1.28)$ & .25 & 3.8 & $1.32(0.95-1.83)$ & .09 & 1.7 & $1.45(0.89-2.35)$ & .13 \\
\hline $\begin{array}{l}\text { At least one smoking parent }+ \text { Smoking best } \\
\text { friend }\end{array}$ & 23.1 & $1.45(1.17-1.81)$ & .001 & 6.5 & $1.61(1.06-2.42)$ & .02 & 3.7 & $2.43(1.37-4.31)$ & .002 \\
\hline$P$ for trend & & & .02 & & & .01 & & & .03 \\
\hline
\end{tabular}

a cross-sectional design and the existence of confounding variables. A recent study showed that students with asthma had a higher inclination to smoke than those without asthma. ${ }^{39}$ As a potential confounder, stressful life events in adolescents were significantly related to both asthma and asthma morbidity. At the same time, adolescents with asthma tended to cope with stressful life events by smoking..$^{40}$ Although exercise is closely related to asthma in adolescents, ${ }^{41}$ we did not find different results from the logistic regression models after excluding exercise in the sensitivity test. Other possible risk factors of asthma, such as obesity, ${ }^{42}$ were also not included in this analysis. Furthermore, no in- 


\section{The Associations of Asthma Symptoms With Active and Passive Smoking}

formation regarding the level of pollution of local areas of students' residence was available. Environmental pollutants are important factors contributing to respiratory problems in children. ${ }^{43}$ Future studies should investigate the sustainability of the asthma symptoms in adolescents at different stages of smoking, with special consideration of environmental factors in Hong Kong. ${ }^{44}$

\section{Conclusions}

This study supports the previous findings that both active and passive smoking are related to asthma symptoms in adolescents. Both non-smoking and smoking adolescents should be protected against secondhand exposure to prevent occurrence of asthma.

\section{ACKNOWLEDGMENTS}

This project was granted funds by the Action Committee Against Narcotics of the Hong Kong Government.

\section{REFERENCES}

1. The International Study of Asthma and Allergies in Childhood (ISAAC) Steering Committee. Worldwide variation in prevalence of symptoms of asthma, allergic rhinoconjunctivitis, and atopic eczema. Lancet 1998;351(9111):1225-1232.

2. Akinbami LJ, Moorman JE, Garbe PL, Sondik EJ. Status of childhood asthma in the United States, 1980-2007. Pediatrics 2009; 123(Suppl 3):S131-S145.

3. Myers MG, Brown SA. Smoking and health in substance-abusing adolescents: a two-year follow-up. Pediatrics 1994;93(4):561-566.

4. Henderson AJ. The effects of tobacco smoke exposure on respiratory health in school-aged children. Paediatr Respir Rev 2008;9(1):21-27.

5. Bhargava EK, Khaliq F. Effect of paternal smoking on the pulmonary functions of adolescent males. Indian J Physiol Pharmacol 2008; 52(4):413-419.

6. De Sario M, Forastiere F, Viegi G, Simoni M, Chellini E, Piccioni P, et al. Parental smoking and respiratory disorders in childhood. Epidemiol Prev 2005;29(2 Suppl):52-56.

7. Lacroix VJ. Exercise-induced asthma. Phys Sportsmed 1999;27(12): 75-92.

8. Lukrafka JL, Fuchs SC, Moreira LB, Picon RV, Fischer GB, Fuchs FD. Performance of the ISAAC questionnaire to establish the prevalence of asthma in adolescents: a population-based study. J Asthma 2010;47(2):166-169.

9. Yoo S, Kim HB, Lee SY, Kim BS, Kim JH, Yu J, et al. Effect of active smoking on asthma symptoms, pulmonary function, and BHR in adolescents. Pediatr Pulmonol 2009;44(10):954-961.

10. Mallol J, Castro-Rodriguez JA, Cortez E. Effects of active tobacco smoking on the prevalence of asthma-like symptoms in adolescents. Int J Chron Obstruct Pulmon Dis 2007;2(1):65-69.

11. Hong SJ, Lee MS, Sohn MH, Shim JY, Han YS, Park KS, et al. Self-reported prevalence and risk factors of asthma among Korean adolescents: 5-year follow-up study, 1995-2000. Clin Exp Allergy 2004;34(10):1556-1562.

12. Jarvis MJ, Feyerabend C, Bryant A, Hedges B, Primatesta P. Passive smoking in the home: plasma cotinine concentrations in non-smokers with smoking partners. Tob Control 2001;10(4):368-374.

13. Lampert T. Smoking and passive smoking exposure in young people: results of the German Health Interview and Examination Survey for
Children and Adolescents (KiGGS). Dtsch Arztebl Int 2008;105(15): 265-271.

14. Marano C, Schober SE, Brody DJ, Zhang C. Secondhand tobacco smoke exposure among children and adolescents: United States, 20032006. Pediatrics 2009;124(5):1299-1305.

15. Rachiotis G, Siziya S, Muula AS, Rudatsikira E, Papastergiou P, Hadjichristodoulou C. Determinants of exposure to Environmental Tobacco Smoke (ETS) among non smoking adolescents (aged 11-17 years old) in Greece: results from the 2004-2005 GYTS Study. Int J Environ Res Public Health 7(1):284-290.

16. Kandel DB, Schaffran C, Griesler PC, Hu MC, Davies M, Benowitz N. Salivary cotinine concentration versus self-reported cigarette smoking: three patterns of inconsistency in adolescence. Nicotine Tob Res 2006;8(4):525-537.

17. Racicot S, McGrath JJ, O'Loughlin J. An investigation of social and pharmacological exposure to secondhand tobacco smoke as possible predictors of perceived nicotine dependence, smoking susceptibility, and smoking expectancies among never-smoking youth. Nicotine Tob Res 2011;13(10):926-933.

18. Vazquez Nava F, Saldivar Gonzalez AH, Martinez Perales G, Lin Ochoa D, Barrientos Gomez MC, Vazquez Rodriguez EM, et al. Associations between family history of allergy, exposure to tobacco smoke, active smoking, obesity, and asthma in adolescents. Arch Bronconeumol 2006;42(12):621-626.

19. Wang HY, Wong GW, Chen YZ, Ferguson AC, Greene JM, Ma Y, et al. Prevalence of asthma among Chinese adolescents living in Canada and in China. CMAJ 2008;179(11):1133-1142.

20. Wong GW, Leung TF, Ko FW, Lee KK, Lam P, Hui DS, et al. Declining asthma prevalence in Hong Kong Chinese schoolchildren. Clin Exp Allergy 2004;34(10):1550-1555.

21. Balding J. Young people in 1998 and looking back as far as 1983: the health related behaviour questionnaire results for 18,221 young people aged 12-13 and 14-15 in 1998, and approximately 200,000 since 1983. Exeter, UK: University of Exeter School Health Education Unit; 1999.

22. Mak K, Day J. Dental health behaviours among early adolescents in Hong Kong. Int J Dent Hyg 2010;9(2):122-126.

23. Mak KK, Day JR. Secular trends of sports participation, sedentary activity and physical self-perceptions in Hong Kong adolescents, 1995-2000. Acta Paediatr 2010;99(11):1731-1734.

24. Arday DR, Giovino GA, Schulman J, Nelson DE, Mowery P, Samet JM. Cigarette smoking and self-reported health problems among US high school seniors, 1982-1989. Am J Health Promot 1995;10(2):111116.

25. Mak KK, Ho SY, Thomas GN, Lo WS, Cheuk DK, Lai YK, et al. Smoking and sleep disorders in Chinese adolescents. Sleep Med 2010;11(3):268-273.

26. Tager IB, Munoz A, Rosner B, Weiss ST, Carey V, Speizer FE. Effect of cigarette smoking on the pulmonary function of children and adolescents. Am Rev Respir Dis 1985;131(5):752-759.

27. Van Miert E, Sardella A, Bernard A. Biomarkers of early respiratory effects in smoking adolescents. Eur Respir J 2011;38(6):1287-1293.

28. Moyes CD, Waldon J, Ramadas D, Crane J, Pearce N. Respiratory symptoms and environmental factors in schoolchildren in the Bay of Plenty. N Z Med J 1995;108(1007):358-361.

29. Vlaski E, Stavric K, Seckova L, Kimovska M, Isjanovska R. Do household tobacco smoking habits influence asthma, rhinitis and eczema among 13-14 year-old adolescents? Allergol Immunopathol (Madr) 2011;39(1):39-44.

30. Sherrill DL, Martinez FD, Lebowitz MD, Holdaway MD, Flannery EM, Herbison GP, et al. Longitudinal effects of passive smoking on pulmonary function in New Zealand children. Am Rev Respir Dis 1992;145(5):1136-1141.

31. Annesi-Maesano I, Oryszczyn MP, Raherison C, Kopferschmitt C, Pauli G, Taytard A, et al. Increased prevalence of asthma and allied 


\section{The Associations of Asthma Symptoms With Active and Passive Smoking}

diseases among active adolescent tobacco smokers after controlling for passive smoking exposure. A cause for concern? Clin Exp Allergy 2004;34(7):1017-1023.

32. Withers NJ, Low L, Holgate ST, Clough JB. The natural history of respiratory symptoms in a cohort of adolescents. Am J Respir Crit Care Med 1998;158(2):352-357.

33. Halterman JS, Conn KM, Hernandez T, Tanski SE. Parent knowledge, attitudes, and household practices regarding SHS exposure: a case-control study of urban children with and without asthma. Clin Pediatr (Phila) 2010;49(8):782-789.

34. Ho SY, Lai HK, Wang MP, Lam TH. Exposure to secondhand smoke and academic performance in non-smoking adolescents. J Pediatr 2010;157(6):1012-1017. e1011.

35. Lai MK, Ho SY, Lam TH. Perceived peer smoking prevalence and its association with smoking behaviours and intentions in Hong Kong Chinese adolescents. Addiction 2004;99(9):1195-1205.

36. Garcia-Marcos L, Quiros AB, Hernandez GG, Guillen-Grima F, Diaz CG, Urena IC, et al. Stabilization of asthma prevalence among adolescents and increase among schoolchildren (ISAAC phases I and III) in Spain. Allergy 2004;59(12):1301-1307.

37. Furu K, Skurtveit S, Langhammer A, Nafstad P. Use of anti-asthmatic medications as a proxy for prevalence of asthma in children and adolescents in Norway: a nationwide prescription database analysis. Eur J Clin Pharmacol 2007;63(7):693-698.

38. Kropp RY, Halpern-Felsher BL. Adolescents' beliefs about the risks involved in smoking "light" cigarettes. Pediatrics 2004;114(4):e445e451.

39. Ringlever L, Otten R, Van Schayck OC, Engels RC. Early smoking in school-aged children with and without a diagnosis of asthma. Eur J Public Health 2012;22(3):394-398.

40. Turyk ME, Hernandez E, Wright RJ, Freels S, Slezak J, Contraras A, et al. Stressful life events and asthma in adolescents. Pediatr Allergy Immunol 2008;19(3):255-263.

41. Oseid S. Asthma and physical activity. Scand J Soc Med 1982; 29(Suppl):227-234

42. Holguin F, Bleecker ER, Busse WW, Calhoun WJ, Castro M, Erzurum SC, et al. Obesity and asthma: an association modified by age of asthma onset. J Allergy Clin Immunol 2011;127(6):1486-1493. e1482.

43. Pierse N, Rushton L, Harris RS, Kuehni CE, Silverman M, Grigg J. Locally generated particulate pollution and respiratory symptoms in young children. Thorax 2006;61(3):216-220.

44. Leung R, Lam CW, Chan A, Lee M, Chan IH, Pang SW, et al. Indoor environment of residential homes in Hong Kong: relevance to asthma and allergic disease. Clin Exp Allergy 1998;28(5):585-590.

This article is approved for Continuing Respiratory Care Education credit. For information and to obtain your CRCE

(free to AARC members) visit

www.rcjournal.com 